\author{
Federal Reserve Bank of Dallas \\ Globalization and Monetary Policy Institute \\ Working Paper No. 342 \\ https://doi.org/10.24149/gwp342
}

\title{
Explosive Dynamics in House Prices? An Exploration of Financial Market Spillovers in Housing Markets Around the World*
}

\author{
Enrique Martínez-García \\ Federal Reserve Bank of Dallas \\ and Southern Methodist University
}

\author{
Valerie Grossman \\ Federal Reserve Bank of Dallas
}

July 2018

\begin{abstract}
Asset prices in general, and real house prices in particular, are often characterized by a nonlinear data-generating process which displays mildly explosive behavior in some periods. Here, we investigate the effect of asset market spillovers on the emergence of explosiveness in the dynamics of real house prices. The recursive unit root test of Phillips et al. (2015a, b) detects and date-stamps statistically-significant periods of mildly explosive behavior. With that methodology, we establish a timeline of periodically-collapsing episodes of explosiveness for a panel of 23 countries from the Federal Reserve Bank of Dallas' International House Price Database (Mack and Martínez-García (2011)) between first quarter 1975 and fourth quarter 2015. Motivated by the theoretical notion of financial spillovers, we examine within a dynamic panel logit framework whether macro fundamentals-and, more specifically, financial variables-help predict episodes of explosiveness. Spreads in yields and real stock market growth together with standard macro variables (growth in personal disposable income per capita and inflation) are found empirically to be among the best predictors. We therefore conclude that financial developments in other asset markets play a significant role in the emergence of explosiveness in real house prices.
\end{abstract}

Keywords: Financial Spillovers; Mildly Explosive Time Series; Right-Tailed Unit-Root Tests; Dynamic Panel Logit Model; International Housing Markets

JEL classification: C22; G12; R30; R31

\footnotetext{
${ }^{*}$ We would like to thank Nathan S. Balke, Christiane Baumeister, Itamar Caspi, John V. Duca, W. Scott Frame, Joshua Gallin, William C. Gruben, María Teresa Martínez-García, Efthymios G. Pavlidis, Ivan Paya, Erwan Quintin, Joseph S. Tracy, Mark A. Wynne, and Alisa Yusupova for many helpful suggestions and comments. We also acknowledge the assistance provided by Michael Weiss and the support of the Federal Reserve Bank of Dallas. All remaining errors are ours alone. The views expressed in this paper are those of the authors and do not necessarily reflect the views of the Federal Reserve Bank of Dallas or the Federal Reserve System.

"Corresponding author.

E-mail addresses: emg.economics@gmail.com (E. Martinez-Garcia), valerie.grossman@dal.frb.org (V. Grossman).
} 


\section{Introduction}

Following the housing boom of the early- and mid-2000s and subsequent collapse leading to the 2008 global recession, there has been a growing interest in detecting bubble-like behavior and its propagation in real estate markets (e.g., Phillips and Yu (2011); Pavlidis et al. (2016); Engsted et al. (2016); Yusupova et al. (2016); Shi (2017); Hu and Oxley (2018)). A popular approach in many of these studies is the use of recursive unit root tests to detect mildly explosive dynamics (whereby the autoregressive coefficient deviates moderately above unity) in real house prices. Mildly explosive behavior is modeled empirically by an autoregressive process with a root that exceeds unity but remains within the vicinity of one and approaches unity as the sample size tends to infinity, as in Phillips and Magdalinos (2007a, 2007b) and Magdalinos (2012).

The definition of mildly explosive dynamics proposed by Phillips and Magdalinos (2007a, 2007b) and Magdalinos (2012) represents a small departure from martingale behavior, but one that is consistent with the submartingale property commonly used to describe rational bubbles in the asset-pricing literature. Hence, periodically-collapsing housing bubbles appear as a plausible (and theoretically-consistent) explanation for the evidence of real house price exuberance. ${ }^{1}$ Diba and Grossman (1988a; 1988b) were among the first to argue that within the standard asset- pricing equation framework, given a constant discount factor, the detection of such a data deviation under the submartingale property can indeed arise from non-fundamental (bubble-like) behavior. A similar argument about bubble-like behavior in real house prices is made in Pavlidis et al. (2016) based on the asset-pricing equation model for housing (Clayton (1996); Hiebert and Sydow (2011); among others).

Still, fundamental factors rather than bubbles can also prompt explosive dynamics-in particular, fundamentals that operate through the discount factor in the asset-pricing equation for housing-which complicates the interpretation of these recursive unit root tests. We show in theory how financial spillovers operate through arbitrage between housing and alternative

\footnotetext{
${ }^{1}$ Exuberance is the term often used in the literature to refer to instances of mildly explosive behavior. Henceforth, we use both expressions interchangeably.
} 
investment asset classes leading to time-variation in the discount factor and potentially episodes of mildly explosive dynamics in real house prices.

Diba and Grossman (1988a; 1988b) were also among the seminal papers to propose the use of unit root and cointegration tests for detecting mildly explosive behavior in the data. However, standard unit root tests are known to have extremely low power in detecting episodes of explosive behavior in asset prices that end with a large drop. Such nonlinear dynamics, consistent with the presence of periodically-collapsing episodes of mildly explosive behavior, can frequently lead to finding spurious stationarity even though the underlying asset-price process is inherently explosive (Blanchard and Watson (1982); Sargent (1987); Diba and Grossman (1988a; 1988b); Evans (1991); Gurkaynak (2008)). A new class of recursive (righttailed) unit root tests proposed by Phillips and Yu (2011) and Phillips et al. (2015a,b) particularly the Generalized Sup ADF (GSADF) from Phillips et al. $(2015 a, b)$ used in this paperhas been widely employed to investigate one or multiple instances of mildly explosive dynamics.

The recursive unit root GSADF test can overcome the lack of power in identifying multiple episodes of periodically-collapsing, mildly explosive behavior within-sample. The GSADF test alleviates this problem with a recursive implementation that, by utilizing subsamples of the data, better identifies periods of explosiveness (as shown in Homm and Breitung (2012)). ${ }^{2}$ However, different forces (fundamental and nonfundamental) can still generate the kind of explosiveness uncovered with these recursive unit root tests in asset prices.

In this paper, we pose a question of direct practical relevance to policymakers as well as to applied researchers: What is the empirical impact of financial spillovers in the emergence of episodes of mildly explosive behavior in real estate prices (and what mechanics of financial arbitrage are at play)? We use the date-stamping strategy under the GSADF methodology to

\footnotetext{
${ }^{2}$ Conventional testing methods for detecting evidence consistent with the presence of rational bubbles in the time series include unit root and cointegration tests (Diba and Grossman (1988a; 1988b)), variance bound tests (LeRoy and Porter (1981); Shiller (1981)), specification tests (West (1987)), and Chow and CUSUM-type tests (Homm and Breitung (2012)).
} 
establish a chronology of episodes of exuberance for the 23 countries in the Federal Reserve Bank of Dallas' International House Price Database (Mack and Martínez-García (2011)).

Given the chronology of episodes of exuberance, we use a dynamic panel logit model to show how explosive dynamics in real house prices are, consistent with theory, partly driven by fundamental behavior tied to housing demand factors, such as real personal disposable income growth per capita and inflation. Most importantly, we document a statistically significant role for financial spillovers from alternative asset classes-based on yield spreads, real stock market valuation gains, and real oil price growth - that can signal shifts in the discount factor under financial arbitrage and the asset-pricing model for housing. Arbitrage across different asset classes is the main force explaining the spillovers into real house price explosiveness. Our findings reinforce the view that housing market exuberance is partly driven by financial fundamentals and highlights the usefulness of recursive (right-tailed) unit root tests such as the GSADF test for monitoring housing markets.

The remainder of the paper is structured as follows: Section 2 provides a derivation of the asset-pricing model for housing augmented to include alternative asset classes for investment and highlights the role of arbitrage as a driver for financial spillovers. Section 3 outlines the GSADF test of Phillips et al. (2015a,b) and the date-stamping methodology that we use to identify in-sample episodes of exuberance in international housing markets. Section 4 discusses the implications of our evidence on exuberance with the help of a dynamic logit model. This section also establishes the empirical impact of fundamentals-and particularly of financial fundamentals-in explaining the emergence of explosiveness in our dataset. Section 5 concludes by showcasing the evidence of financial spillovers in propagating exuberance into housing markets, while the Appendix provides additional technical details on the recursive implementation of the unit root tests. 


\section{A Stylized Model of Financial Arbitrage}

Let us define the intertemporal marginal rate of substitution as $M_{t, t+1} \equiv \beta \frac{M U_{t+1}}{M U_{t}}$, where $M U_{t+1}$ is the marginal utility at time $t+1$ and $0<\beta<1$ is the intertemporal discount factor. The gross rate of return on investment in a housing unit can be expressed as $I_{t+1}^{h} \equiv \frac{P_{t+1}+R_{t+1}}{P_{t}}$, where $P_{t+1}$ is the price of a housing unit, $R_{t+1}$ is the housing rental income (either actual if the housing unit is rented or imputed if owner-occupied) at $t+1$, and $(1-b)$ is the payout ratio that determines the rental income from housing $R_{t+1} \equiv(1-b) Y_{t+1}$ after netting out expenses such as maintenance costs, taxes, reinvestment, etc. from the flow of (actual or imputed) housing earnings $Y_{t+1}$. We allow earnings from investing in a housing unit $\left(Y_{t}\right)$ to follow a general autoregressive process of order 1 ,

$$
Y_{t}=\varphi Y_{t-1}+\epsilon_{t}, \epsilon_{t} \sim W N\left(0, \sigma_{\epsilon}^{2}\right)
$$

where $\varphi$ is unrestricted to take values in the I(0), I(1), and mildly-explosive regions, and $\epsilon_{t}$ is an independent and identically-distributed (iid) white noise stochastic process.

We also consider an alternative risky asset class for investment purposes whose gross return at time $t+1$ is denoted as $I_{t+1}^{s}$. We express the canonical asset-pricing equation for the alternative risky asset as

$$
1=E_{t}\left[M_{t, t+1} I_{t+1}^{S}\right]=E_{t}\left[M_{t, t+1}\right] E_{t}\left[I_{t+1}^{S}\right]+\operatorname{cov}_{t}\left(M_{t, t+1}, I_{t+1}^{S}\right)
$$

The following no-arbitrage condition between housing and the alternative risky asset must also hold

$$
0=E_{t}\left[M_{t, t+1}\left(I_{t+1}^{h}-I_{t+1}^{S}\right)\right]=E_{t}\left[M_{t, t+1}\right] E_{t}\left[I_{t+1}^{h}-I_{t+1}^{s}\right]+\operatorname{cov}_{t}\left(M_{t, t+1}, I_{t+1}^{h}-I_{t+1}^{s}\right)
$$

For tractability, we adopt the simplifying assumption that excess returns on housing relative to those attainable with the alternative risky investment are uncorrelated with the intertemporal marginal rate of substitution $M_{t, t+1}$-i.e., $\operatorname{cov}_{t}\left(M_{t, t+1}, I_{t+1}^{h}-I_{t+1}^{s}\right)=0$. This implies that the no-arbitrage condition in (3) simply becomes

$$
0=E_{t}\left[I_{t+1}^{h}-I_{t+1}^{s}\right]
$$


which says that expected returns on housing investment must equate those of the alternative risky asset ex-ante. ${ }^{3}$

A risk-free asset gives a certain gross return at $t+1$, denoted $I_{t+1}^{f}$, such that $E_{t}\left[I_{t+1}^{f}\right]=I_{t+1}^{f}$ and $\operatorname{cov}_{t}\left(M_{t, t+1}, I_{t+1}^{f}\right)=0$. Therefore, the corresponding asset-pricing equation would imply that

$$
I_{t+1}^{f}=\frac{1}{E_{t}\left[M_{t, t+1}\right]}
$$

Hence, from (2) and (5), the expected excess return on the alternative risky asset can be expressed as

$$
E_{t}\left[I_{t+1}^{S}\right]-I_{t+1}^{f}=-I_{t+1}^{f} \operatorname{cov}_{t}\left(M_{t, t+1}, I_{t+1}^{S}\right)
$$

which is akin to the conditional capital asset-pricing model (CAPM). ${ }^{4}$ Naturally, equation (6) can be rewritten as $E_{t}\left[I_{t+1}^{s}\right]-I_{t+1}^{f}=s p_{t}^{s, f}$ where $s p_{t}^{s, f} \equiv-\frac{\operatorname{cov}_{t}\left(M_{t, t+1}, I_{t+1}^{s}\right)}{E_{t}\left[M_{t, t+1}\right]}$ is the conventional riskpremium priced on the alternative asset class relative to the risk-free rate.

Assuming the intertemporal marginal rate of substitution and the return on the alternative asset follow a bivariate (mean-preserving) log-normal distribution such that $\left(\begin{array}{c}\ln \left(M_{t, t+1}\right) \\ \ln \left(I_{t+1}^{s}\right)\end{array}\right) \sim N\left(\left(\begin{array}{c}\mu_{m}-\frac{\sigma_{m}^{2}}{2} \\ \mu_{s}-\frac{\sigma_{s}^{2}}{2}\end{array}\right),\left(\begin{array}{cc}\sigma_{m}^{2} & \rho_{s m} \sigma_{s} \sigma_{m} \\ \rho_{s m} \sigma_{s} \sigma_{m} & \sigma_{s}^{2}\end{array}\right)\right)$, we obtain that the risk-free rate is constant and equal to $I^{f} \equiv e^{-\mu_{m}}$. Furthermore, we also find that $\operatorname{cov}_{t}\left(M_{t, t+1}, I_{t+1}^{S}\right)=$ $e^{\mu_{m}+\mu_{s}}\left(e^{\rho_{s m} \sigma_{s} \sigma_{m}}-1\right)$. As a result, we can rewrite equation (6) as

$$
E_{t}\left[I_{t+1}^{s}\right]=I^{f}+s p^{s, f}, s p^{s, f} \equiv e^{\mu_{s}}\left(1-e^{\rho_{s m} \sigma_{s} \sigma_{m}}\right),
$$

\footnotetext{
${ }^{3}$ More generally, we can establish that whenever $\operatorname{cov}_{t}\left(M_{t, t+1}, I_{t+1}^{h}-I_{t+1}^{s}\right) \neq 0$, equation (4) can be generalized as follows:sp $p_{t}^{h, s}=E_{t}\left[I_{t+1}^{h}-I_{t+1}^{s}\right]$ where $s p_{t}^{h, s} \equiv-\frac{\operatorname{cov}_{t}\left(M_{t, t+1,}, I_{t+1}^{h}-I_{t+1}^{s}\right)}{E_{t}\left[M_{t, t+1}\right]}$ is the priced risk-spread between housing and the alternative asset class.

${ }^{4}$ The covariance plays an important role in the CAPM model as it enters into the conditional beta $\beta_{t}^{s} \equiv$ $\frac{\operatorname{cov}_{t}\left(M_{t, t+1,} I_{t+1}^{S}\right)}{\operatorname{var}_{t}\left(M_{t, t+1}\right)}$, where $\beta_{t}^{s}$ is the coefficient of a regression of the return $I_{t+1}^{S}$ on the macro factor $M_{t, t+1}$.
} 
where we consider only parameterizations such that $I^{f}+s p^{s, f}>0$. The risk-premium $s p^{s, f}$ implies that $E_{t}\left[I_{t+1}^{S}\right]>I^{f}$ if and only if $\rho_{s m}<0$. Hence, a positive risk-premium arises whenever returns on the alternative risky asset are negatively correlated with the intertemporal marginal rate of substitution (that is, if the returns of the alternative risky asset are high in good times when the intertemporal marginal utility of substitution is low). Given $\rho_{s m}<0$, we find that a positive risk-premium ought to be higher, all else equal, with higher standard deviation of the macro factor $\left(\sigma_{m}\right)$ or higher standard deviation of the alternative risky asset returns $\left(\sigma_{s}\right)$.

\subsection{The Present-Value Model of House Prices}

Now, the asset-pricing equation in (7) and the no-arbitrage condition in (4) yield the following expression for house prices

$$
E_{t}\left[\frac{P_{t+1}+R_{t+1}}{P_{t}}\right]=E_{t}\left[I_{t+1}^{h}\right]=E_{t}\left[I_{t+1}^{s}\right]=I^{f}+s p^{s, f},
$$

and

$$
P_{t}=\frac{1}{E_{t}\left[I_{t+1}^{s}\right]} E_{t}\left[P_{t+1}+(1-b) Y_{t+1}\right]=\frac{1}{I^{f}+s p^{s, f}} E_{t}\left[P_{t+1}+(1-b) Y_{t+1}\right]
$$

where $E_{t}\left[I_{t+1}^{S}\right]$ defines the economically-relevant discount factor for housing. This difference equation shows that today's price of a housing unit $\left(P_{t}\right)$ must be equal to the discounted value of tomorrow's expected rental income (the payout component of tomorrow's housing earnings $\left.Y_{t+1}\right)$ plus tomorrow's resale price of housing. We discount using the expected rate of return on an alternative risky investment-which incorporates a risk-premium $\left(s p^{s, f}\right)$ above and beyond the risk-free rate $\left(I^{f}\right)$ in order to compensate for risks to investors. The risk-premium component $\left(s p^{s, f} \equiv f\left(\sigma_{m}, \sigma_{s} ;\right)\right)$ prices macro risks such as those arising from macro volatility $\left(\sigma_{m}\right)$ and asset price volatility $\left(\sigma_{s}\right)$, among others.

By recursively substituting forward, equation (9) can be rewritten as 


$$
P_{t}=(1-b) E_{t}\left[\sum_{j=1}^{+\infty}\left(\frac{1}{I^{f}+s p^{s, f}}\right)^{j} Y_{t+j}\right]+\lim _{T \rightarrow+\infty} E_{t}\left[\left(\frac{1}{I^{f}+s p^{s, f}}\right)^{T} P_{t+T}\right]
$$

The rational-expectations solution to the present-value model implied by the difference equation (9) consists of a fundamental component, $P_{t}^{*}$, and a periodically-collapsing rational bubble, $B_{t}$, such that $P_{t}=P_{t}^{*}+B_{t}$ (Blanchard and Watson (1982); Sargent (1987); Diba and Grossman (1988a; 1988b); Evans (1991)). Imposing the transversality condition $\lim _{T \rightarrow+\infty} E_{t}\left[\left(\frac{1}{I^{f}+s p^{s, f}}\right)^{T} P_{t+T}^{*}\right]=0$ to rule out non-fundamental behavior (rational bubbles), the unique (nonexplosive) solution to (10) whenever $I^{f}+s p^{s, f}-\varphi>0$ yields

$$
P_{t}^{*}=\left(\frac{\varphi}{I^{f}+s p^{s, f}-\varphi}\right)(1-b) Y_{t}
$$

a straightforward analog of the discounted dividend model (Gordon and Shapiro 1956) for housing. It follows from (1) and (11) that the fundamental dynamics of the house price follow this general autoregressive process

$$
P_{t}^{*}=\varphi P_{t-1}^{*}+\left(\frac{\varphi}{I^{f}+s p^{s, f}-\varphi}\right)(1-b) \epsilon_{t}
$$

inheriting the autoregressive coefficient $\varphi$ directly from the fundamental process in (1).

The implication that economic fundamentals solely explain house prices depends crucially on the transversality condition. Whenever this condition is violated (i.e., whenever $\lim _{T \rightarrow+\infty} E_{t}\left[\left(\frac{1}{I^{f}+s p^{s, f}}\right)^{T} P_{t+T}\right]=0$ does not hold), there exist infinite forward solutions to the difference equation for the house price $P_{t}=P_{t}^{*}+B_{t}$ where the rational bubble component $B_{t}$ satisfies the submartingale property ${ }^{5}$

$$
E_{t}\left[B_{t+1}\right]=\left(I^{f}+s p^{s, f}\right) B_{t}
$$

\footnotetext{
${ }^{5}$ The gross return on a unit of housing can be expressed as $I_{t}^{h}=\frac{P_{t}^{*}+(1-b) Y_{t}+B_{t}}{P_{t-1}^{*}+B_{t-1}}=\left(\frac{\frac{{ }^{f}+s p^{s, f}}{\varphi}+\frac{B_{t}}{P_{t}^{*}}}{1+\frac{B_{t-1}}{P_{t-1}^{*}}}\right)\left(\frac{P_{t}^{*}}{P_{t-1}^{*}}\right)$ where we assume $\frac{I^{f}+s p^{s, f}}{\varphi}>1$
} 
Since the discount factor is positive by assumption $\left(I^{f}+s p^{s, f}>0\right)$, the term $B_{t}$ is expected to be explosive. Hence, it follows that house prices can display explosive dynamics because of the emergence of rational bubbles. Yet, factors other than bubbles can also give rise to explosive dynamics in house prices-including financial spillovers.

\subsection{Financial Spillovers and Mildly Explosive Behavior}

A number of fundamental-based factors can give rise to explosiveness in house prices. One possibility is that $\varphi$ exceeds unity implying that house prices inherit explosive dynamics from fundamentals rather than from a non-fundamental bubble. Another possibility is time-variation in the discount factor. In particular, we highlight in this paper the role of the risk-premium $\left(s p^{s, f}\right)$ of the alternative risky asset which directly affects the discount factor in the assetpricing equation for housing.

To illustrate this point, let us assume that $s p_{t+j}^{s, f}$ is a time-varying risk-premium and consider the case where an unexpected, but temporary, increase in spreads is revelated at time $t$. To be more precise, we assume $s p_{t+j}^{s, f}=s p_{L}^{s, f}>0$ for $j=\cdots,-2,-1, s p_{t+j}^{s, f}=s p_{H}^{s, f}>s p_{L}^{s, f}$ for $j=$ $0, \ldots, T_{s}\left(T_{s} \geq 0\right)$, and $s p_{t+j}^{s, f}=s p_{L}^{s, f}>0$ for $j=T_{s}+1, T_{s}+2, \ldots$ Given this and (12), fundamental-based house prices follow

$$
\begin{gathered}
P_{t+j}^{*}=\left(\frac{\varphi}{I^{f}+s p_{L}^{s, f}-\varphi}\right)(1-b) Y_{t+j}, \text { for } j=T_{s}+1, T_{s}+2, T_{s}+3, \ldots \\
P_{t+j}^{*}=\varphi P_{t+j-1}^{*}+\left(\frac{\varphi(1-b)}{I^{f}+s p_{L}^{s, f}-\varphi}\right) \epsilon_{t+j}, \text { for } j=T_{s}+2, T_{s}+3, \ldots
\end{gathered}
$$

Using (14) and backward induction on the difference equation in (9) together with the fundamental process in (1), we obtain that house prices at $j=T_{s}$ become equal to

$$
P_{t+T_{S}}^{*}=\left(\frac{I^{f}+s p_{L}^{s, f}}{I^{f}+s p_{H}^{s, f}}\right)\left(\frac{\varphi}{I^{f}+s p_{L}^{s, f}-\varphi}\right)(1-b) Y_{t+T_{s}} .
$$


Hence, combining the housing price in (14) and that in (15) with the process for the fundamentals in (1), we obtain that for $j=T_{s}+1$, it holds that

$$
P_{t+T_{S}+1}^{*}=\varphi\left(\frac{I^{f}+s p_{H}^{s, f}}{I^{f}+s p_{L}^{s, f}}\right) P_{t+T_{S}}^{*}+\left(\frac{\varphi(1-b)}{I^{f}+s p_{L}^{s, f}-\varphi}\right) \epsilon_{t+T_{S}+1}
$$

where $\frac{I^{f}+s p_{H}^{s, f}}{I^{f}+s p_{L}^{s, f}}>1$ under a standard parameterization that ensures $I^{f}+s p_{L}^{s, f}>0$. As a result, equation (16) shows how unexpected risk-spread shocks can spill onto house price dynamics and-under some mild conditions (i.e., if $\varphi\left(\frac{I^{f}+s p_{H}^{s, f}}{I^{f}+s p_{L}^{s, f}}\right)>1$ )-lead to instances of explosive behavior (episodes of exuberance) in the time series even when we rule out non-fundamental behavior (bubbles) in house prices.

Similarly, at $j=T_{s}-1$ we find that

$$
P_{t+T_{S}-1}^{*}=\left\{\begin{array}{c}
\left(\frac{I^{f}+s p_{L}^{s, f}-\left(\frac{s p_{H}^{s, f}-s p_{L}^{s, f}}{{ }^{f}+s p_{H}^{s, f}}\right) \varphi}{I^{f}+s p_{H}^{s, f}}\right)\left(\frac{\varphi}{I^{f}+s p_{L}^{s, f}-\varphi}\right)(1-b) Y_{t+T_{s}-1}, \text { if } s p_{t+T_{s}-1}^{s, f}=s p_{H}^{s, f}, \\
\left(\frac{I^{f}+s p_{L}^{s, f}}{I^{f}+s p_{H}^{s, f}}\right)\left(\frac{\varphi}{I^{f}+s p_{L}^{s, f}-\varphi}\right)(1-b) Y_{t+T_{s}-1}, \text { if } s p_{t+T_{S}-1}^{s, f}=s p_{L}^{s, f},
\end{array}\right.
$$

from where it follows for $j=T_{s}$ that

$$
P_{t+T_{s}}^{*}=\left\{\begin{array}{c}
\varphi\left(\frac{I^{f}+s p_{L}^{s, f}}{I^{f}+s p_{L}^{s, f}-\left(\frac{s p_{H}^{s, f}-s p_{L}^{s, f}}{I^{f}+s p_{H}^{s, f}}\right) \varphi}\right) P_{t+T_{s}-1}^{*}+\left(\frac{I^{f}+s p_{L}^{s, f}}{I^{f}+s p_{H}^{s, f}}\right)\left(\frac{\varphi(1-b)}{I^{f}+s p_{L}^{s, f}-\varphi}\right) \epsilon_{t+T_{s}}, \text { if } s p_{t+T_{s}-1}^{s, f}=s p_{H}^{s, f}, \\
\varphi P_{t+T_{s}-1}^{*}+\left(\frac{I^{f}+s p_{L}^{s, f}}{{ }^{f}+s p_{H}^{s, f}}\right)\left(\frac{\varphi(1-b)}{I^{f}+s p_{L}^{s, f}-\varphi}\right) \epsilon_{t+T_{s}}, \text { if } s p_{t+T_{s}-1}^{s, f}=s p_{L}^{s, f},
\end{array}\right.
$$

with $\frac{I^{f}+s p_{L}^{s, f}}{I^{f}+s p_{L}^{s, f}-\left(\frac{s p_{H}^{s, f}-s p_{L}^{s, f}}{I^{f}+s p_{H}^{s, f}}\right) \varphi}>1$ whenever $0<I^{f}+s p_{L}^{s, f}-\left(\frac{s p_{H}^{s, f}-s p_{L}^{s, f}}{I^{f}+s p_{H}^{s, f}}\right) \varphi<I^{f}+s p_{L}^{s, f}$.

Equations (16) and (18) illustrate that, under some conditions (i.e., if $\varphi\left(\frac{I^{f}+s p_{H}^{s, f}}{{ }_{I}^{f}+s p_{L}^{s, f}}\right)>1$ and 
$\left.\varphi\left(\frac{I^{f}+s p_{L}^{s, f}}{{ }_{I} f_{+}+s p_{L}^{s, f}-\left(\frac{s p_{H}^{s, f}-s p_{L}^{s, f}}{I^{f}+s p_{H}^{s, f}}\right) \varphi}\right)>1\right)$, an unexpected two-period increase in the spreads can spill over into an episode of exuberance (explosiveness) of up to two periods. ${ }^{6}$

We can characterize the solution recursively in this way for any finite duration of $T_{S}+1$ periods of high-risk-spreads and reach a similar conclusion about the extent to which financial spillovers, operating via the discount factor, can introduce explosiveness in the dynamics of house prices even when we rule out bubbles and when housing market fundamentals pinned down by the $Y_{t}$ process are non-explosive.

\subsection{Main Implications}

The fact that $B_{t}$ is explosive has important implications for house prices in the presence of rational bubbles. If the economic fundamentals in (1) follow either a stationary $(|\varphi|<1)$ or an integrated process of order $1(\varphi=1)$, then the dynamics of fundamental-based prices given by (11) under a constant discount factor-which inherit the autoregressive coefficient $\varphi$ directly from (1)-must display non-explosive behavior, too. Furthermore, house prices and fundamentals are cointegrated in the absence of the bubble term $B_{t}$. This explains how house prices exhibit explosive dynamics in the presence of rational bubbles.

The conventional assumption that $Y_{t}$ in equation (1) is either I(0) or I(1) may not hold, so house prices may inherit their explosiveness from the housing market fundamentals directly. Other fundamentals-based factors can give rise to explosive house price dynamics-even when housing earnings (or housing rents) are non-explosive (i.e., if $Y_{t}$ is either I(0) or I(1)) and we rule out bubbles (see, e.g., Pavlidis et al. (2016)). Within the asset-pricing framework laid out here, time-variation in the discount rate can lead to explosive behavior through financial spillovers from risky alternative assets.

\footnotetext{
${ }^{6}$ We focus here mainly on the induced explosiveness, but it is interesting to note that unexpected changes in the risk spread also alter the volatility of the residuals as can be seen by contrasting equation (18) to (14) and (16).
} 
As shown here, unexpected changes in the risk-spread $\left(s p_{t}^{s, f}\right)$ or, more generally, anything that impacts the economically-relevant discount rate for housing, can lead to episodes of explosive behavior within sample. An unexpected (short-lived and temporary) spike in risk spreads alone implies that the dynamics of fundamental-based house prices in the absence of bubbles become

$$
P_{t+1}^{*}=\delta_{t}\left(\varphi, I^{f}, s p^{s, f} ; b\right) P_{t}^{*}+\epsilon_{t}, \epsilon_{t} \sim i . i . d .\left(0, \sigma_{t}^{2}\left(\varphi, I^{f}, s p^{s, f} ; b\right)\right), \forall t \geq 0,
$$

where $\delta_{t}\left(\varphi, I^{f}, s p^{s, f} ; b\right)$ and $\sigma_{t}^{2}\left(\varphi, I^{f}, s p^{s, f} ; b\right)$ are the first-order autocorrelation and the variance of the residuals, respectively. Both are composite coefficients and depend critically on the discount rate for housing. Our stylized model shows how unexpected risk-spread shocks originating in other risky-asset markets can spill over into housing via the discount rate, generating an episode of explosive behavior whereby $\delta_{t}\left(\varphi, I^{f}, s p^{s, f} ; b\right)>1$ for some periods of time $t$. In the remainder of the paper, we test for the presence of explosiveness in international housing markets and show empirical evidence that such instances are partly predictable based on financial variables involving alternative asset classes-bond spreads, stock market returns-consistent with the theory of financial spillovers discussed here.

\section{Testing Mildly Explosive Behavior}

Phillips and Magdalinos (2007a, 2007b) define a mildly explosive root using the following datagenerating process (DGP) for the observed time series

$$
y_{t}=\delta_{T} y_{t-1}+\epsilon_{t}, \epsilon_{t} \sim i . i . d .\left(0, \sigma^{2}\right)
$$

with the intercept set at zero for simplicity, where $\delta_{T}=1+\frac{c}{T^{\alpha}}, \alpha \in(0,1)$ and $T$ denotes the sample size. Whenever $c>0$, such a root is explosive and approaches unity at a rate slower 
than $O\left(T^{-1}\right)$ as $T \rightarrow \infty .{ }^{7}$ Equation (20) can incorporate episodes of explosiveness as those described by our model of financial spillovers in equation (19) in section 2.

Subtracting $y_{t-1}$ from both sides, the process in (1) can be expressed as $\Delta y_{t}=\beta_{T} y_{t-1}+\epsilon_{t}$, $\epsilon_{t} \sim i . i . d .\left(0, \sigma^{2}\right)$ where $\Delta$ is the difference operator, and $\beta_{T}=\delta_{T}-1$ is the corresponding coefficient to be tested. If serial correlation is a concern, a standard parametric autoregressive approach to deal with it consists in extending equation (1) to an $A R(k+1)$ process (Said and Dickey (1984)). The approach is based on generalizing the process to be $\theta_{k+1}(B) y_{t}=\epsilon_{t}$, where $\theta_{k+1}(B)=1-\theta^{1} B-\cdots-\theta^{k} B^{k}-\theta^{k+1} B^{k+1}$ defines the lag operator. A unit root in $\theta_{k+1}(B)$ corresponds to $\theta_{k+1}(1)=0$. Then, testing for a unit root is more easily performed by rewriting the augmented regression model in the following form ${ }^{8}$

$$
\Delta y_{t}=\beta_{T} y_{t-1}+\sum_{j=1}^{k} \psi^{j} \Delta y_{t-j}+\epsilon_{t}, \epsilon_{t} \sim \text { i.i.d. }\left(0, \sigma^{2}\right),
$$

where $\beta_{T}=-\theta_{k+1}(1)$ and $\psi^{1}=-\left(\theta^{2}+\theta^{3}+\cdots+\theta^{k}+\theta^{k+1}\right), \psi^{2}=-\left(\theta^{3}+\cdots+\theta^{k}+\right.$ $\left.\theta^{k+1}\right), \ldots, \psi^{k}=-\left(\theta^{k+1}\right)$.

\subsection{Generalized Sup ADF (GSADF) Test}

The generalized Sup ADF (GSADF) procedure of Phillips et al. (2015a,b) for detecting mildly explosive behavior consists in recursively applying the Augmented Dickey-Fuller (ADF) test for the null of a unit root against the alternative of a mildly explosive root (the right tail of the distribution) based on the specification in (21). The full sample as being normalized on the interval $[0,1]$ (i.e., divided by the total number of observations $T$ ), so we denote $r_{1}$ and $r_{2}$ the

\footnotetext{
7 Phillips and Magdalinos (2007a, 2007b) and Magdalinos (2012) provide a large-sample asymptotic theory for this class of mildly explosive processes that enables econometric inference, unlike what occurs for purely explosive processes. Autoregressive processes with a purely explosive root, $y_{t}=\delta y_{t-1}+\epsilon_{t}, \epsilon_{t} \sim N I D\left(0, \sigma^{2}\right)$, $|\delta|>1$, were first discussed by White (1958) and Anderson (1959). Assuming a zero initial condition for $y_{t}$, an asymptotic Cauchy limit distribution theory for the OLS/ML estimator exists. However, the asymptotic distribution of the estimator is ultimately dependent on the distributional assumptions imposed on the innovations (Anderson, 1959) - the imposed Gaussianity of the errors cannot be relaxed without changing the asymptotic distribution. Hence, there is no general framework for asymptotic inference on purely explosive processes.

${ }^{8}$ The ADF approach generalizes the Dickey and Fuller (1979) test by parametrically removing the structural autocorrelation in the time series, but otherwise implements the same testing procedure.
} 
corresponding beginning and end of a given subsample (such that $0 \leq r_{1}<r_{2} \leq 1$ ). We denote by $r_{w}=r_{2}-r_{1}$ the window size of the regression estimation, while $r_{0}$ is the fixed initial window required by the econometrician such that the subsample ending in $r_{2}$ satisfies that $r_{2} \in$ $\left[r_{0}, 1\right]$ (i.e., $r_{0}$ is the minimum window size).

The empirical specification used for testing is the following recursive formulation of the ADF auxiliary regression equation in (21):

$$
\Delta y_{t}=a_{r_{1}, r_{2}}+\beta_{r_{1}, r_{2}} y_{t-1}+\sum_{j=1}^{k} \psi_{r_{1}, r_{2}}^{j} \Delta y_{t-j}+\epsilon_{t}, \epsilon_{t} \sim i . i . d .\left(0, \sigma_{r_{1}, r_{2}}^{2}\right)
$$

where $y_{t}$ denotes the generic time series tested for explosiveness, $\Delta y_{t}$ for $j=1, \ldots, k$ are the differenced lags of the time series, and $\epsilon_{t}$ is an i.i.d. error term. Furthermore, $k$ is the maximum number of lags included in the specification, while $a_{r_{1}, r_{2}}, \beta_{r_{1}, r_{2}}$, and $\psi_{r_{1}, r_{2}}^{j}$ for $j=1, \ldots, k$ are the corresponding regression coefficients - the intercept, the autoregressive coefficient, and the coefficients of the lagged first differences-when estimated over the (normalized) subsample beginning in $r_{1}$ and ending in $r_{2}$.

Setting $r_{1}=0$ and $r_{2}=r_{0}=1$ yields the standard ADF test statistic over the full sample, $A D F_{0}^{1}=\frac{\widehat{\beta}_{0,1}}{\text { s.e. }\left(\widehat{\beta}_{0,1}\right)} \cdot{ }^{9}$ In order to deal with the effect of a collapse occurring within sample on the performance of the standard right-tailed ADF test $\left(A D F_{0}^{1}\right)$, Phillips and $Y u(2011)$ proposed a recursive estimation of the ADF regression equation in (22) with a forward expanding estimation subsample where the end of the subsample $r_{2}$ increases from $r_{0} \in(0,1)$ (the fixed minimum size for the initial window) to one (the last available observation). The starting point of each estimation is kept fixed at $r_{1}=0$, so the expanding window size of the regression (over the normalized sample) is simply given by $r_{w}=r_{2}$. Then, incrementing the window size $r_{2} \in$ $\left[r_{0}, 1\right]$ with one additional observation at a time, the recursive estimation of the ADF regression

\footnotetext{
${ }^{9}$ Evans (1991) shows through simulation methods that non-recursive unit root tests like $A D F_{0}^{1}$ (and cointegration tests as well) have low power and frequently cannot reject the null of no explosive behavior even when present in the data. Nonlinear dynamics, such as those displayed by mildly explosive processes, may lead the standard righttailed ADF test to findings of spurious stationarity. This is because increases followed by downward corrections make the process appear mean-reverting and stationary in finite samples even when it is not.
} 
equation in (22) over the forward expanding subsample yields a sequence of $A D F_{0}^{r_{2}}=\frac{\widehat{\beta}_{0, r_{2}}}{\text { s.e. }\left(\widehat{\beta}_{0, r_{2}}\right)}$ statistics. The Phillips et al. (2011) test statistic, called Sup ADF (SADF), is defined as the supremum value of the sequence of $A D F_{0}^{r_{2}}$ statistics expressed as $S A D F\left(r_{0}\right)={ }_{r_{2} \in\left[r_{0}, 1\right]}^{\sup } A D F_{0}^{r_{2}}$.

The rolling-window structure of the $\operatorname{SADF}\left(r_{0}\right)$ test leads to improved power in detecting mildly explosive behavior relative to that of the standard $A D F_{0}^{1}$ test. Furthermore, Homm and Breitung (2012) show through simulation experiments that the $\operatorname{SADF}\left(r_{0}\right)$ test generally outperforms alternative testing methods commonly used to detect a single structural break in the persistence of the process from I(1) to explosive. The alternative tests considered by Homm and Breitung (2012) perform well only when the series becomes explosive but never bursts within sample. While the $S A D F\left(r_{0}\right)$ test performs better because it deals with series where explosiveness occurs and collapses in-sample, its power and its performance deteriorate in the presence of recurring (more than once) and periodically-collapsing episodes of exuberance, as established in Phillips et al. (2015a,b).

Phillips et al. $(2015 a, b)$ proposed another recursive (right-tailed) unit root test, the Generalized SADF (GSADF). The GSADF approach builds on the forward expanding estimation subsample strategy of the SADF procedure, but allows the subsample starting point $r_{1}$ to change. This additional margin of flexibility in the estimation window of the $G S A D F\left(r_{0}\right)$ results in substantial power gains, consistent with multiple and periodically-collapsing episodes of explosiveness in the data.

The initial window size $r_{0}$ satisfies that $r_{0}<r_{2}$, while the expanding window size of the regression (over the normalized sample) is defined as $r_{w}=r_{2}-r_{1}$. Incrementing the window size $r_{2} \in\left[r_{0}, 1\right]$ with an additional observation at a time over each starting point of the sample $r_{1} \in\left[0, r_{2}-r_{0}\right]$, the recursive estimation of the ADF regression equation in (22) yields a sequence of $A D F_{r_{1}}^{r_{2}}=\frac{\widehat{\beta}_{r_{1}, r_{2}}}{\text { s.e. }\left(\widehat{\beta}_{r_{1}, r_{2}}\right)}$ statistics. The Phillips et al. $(2015 \mathrm{a}, \mathrm{b})$ test statistic-the Generalized SADF (GSADF) - is defined as the supremum value of the sequence of $A D F_{r_{1}}^{r_{2}}$ statistics expressed as follows 


$$
\operatorname{GSADF}\left(r_{0}\right)=\sup _{r_{1} \in\left[0, r_{2}-r_{0}\right]}\left\{\sup _{r_{2} \in\left[r_{0}, 1\right]} A D F_{r_{1}}^{r_{2}}\right\}
$$

Under the I(1) null, the limit distribution of the $\operatorname{GSADF}\left(r_{0}\right)$ statistic is given by

$$
\sup _{r_{1} \in\left[0, r_{2}-r_{0}\right], r_{2} \in\left[r_{0}, 1\right]}\left\{\frac{\frac{1}{\frac{1}{2} r_{w}\left[W\left(r_{2}\right)^{2}-W\left(r_{1}\right)^{2}-r_{w}\right]-\int_{r_{1}}^{r_{2}} W(r) d r\left[W\left(r_{2}\right)-W\left(r_{1}\right)\right]}}{r_{w}^{\frac{1}{2}}\left\{r_{w} \int_{r_{1}}^{r_{2}} W(r)^{2} d r-\left[\int_{r_{1}}^{r_{2}} W(r) d r\right]^{2}\right\}^{\frac{1}{2}}}\right\} \text {. Whenever } \operatorname{GSADF}\left(r_{0}\right)
$$

exceeds the corresponding right-tailed critical value from its limit distribution, the unit root hypothesis is rejected in favor of mildly explosive behavior. The rolling-window structure of the $\operatorname{GSADF}\left(r_{0}\right)$ test leads to improved power in detecting recurring episodes of mildly explosive behavior relative to what could be achieved with the standard $A D F_{0}^{1}$ test and with the $\operatorname{SADF}\left(r_{0}\right)$ test. For that reason, we favor the GSADF approach in this study.

\subsection{Date-Stamping under the GSADF Approach}

If the null of a unit root in $y_{t}$ is rejected, then the GSADF procedure can be used to obtain a chronology of exuberance in the data. Phillips et al. (2015a,b) and Pavlidis et al. (2016) recommend establishing a chronology with a dummy variable $E X U_{i, t}$ for a given series $i$ that takes the value of 1 during an episode of exuberance and 0 otherwise, i.e., $E X U_{i, t}=$ $\left\{\begin{array}{l}0, \text { if } B S A D F_{i, t}\left(r_{0}\right)<s c v_{t}^{\alpha}, \\ 1, \text { if } B S A D F_{i, t}\left(r_{0}\right)>s c v_{t}^{\alpha} .\end{array}\right.$ $t=\left\lfloor r_{2} T\right\rfloor$ is based on comparing the Backward Sup ADF (BSADF) statistic $\left(B S A D F_{i, t}\left(r_{0}\right)\right)$ for that observation against the corresponding $100(1-\alpha) \%$ critical value of the Sup ADF $\left(s c v_{t}^{\alpha}\right)$ based on $t=\left\lfloor r_{2} T\right\rfloor$ observations, a sample size of $T$ observations, and a significance level of $\alpha$. The Backward Sup ADF (BSADF) statistic for country $i, B S A D F_{i, t}\left(r_{0}\right)={ }_{t=\left[r_{2} T\right], r_{1} \in\left[0, r_{2}-r_{0}\right]} A D F_{i, r_{1}}^{r_{2}}$, relates to the country $i$ GSADF statistic as follows: $G S A D F_{i}\left(r_{0}\right)=\sup _{r_{2} \in\left[r_{0}, 1\right]} B S A D F_{i, t=\left[r_{2} T\right]}\left(r_{0}\right) .{ }^{10}$

\footnotetext{
${ }^{10}$ The distributions of these test statistics is non-standard and depends on the minimum window size $r_{0}$. Hence, finite sample critical values are obtained through Monte Carlo simulations by generating 2000 replications of a driftless random walk process with $N(0,1)$ errors. Additional information on the bootstrap procedure to derive the critical values can be found in Phillips et al. (2015a,b) and Pavlidis et al. (2016).
} 
Following the recommendation of Phillips et al. (2015a,b) and Pavlidis et al. (2016), we set a minimum duration for each episode of exuberance in constructing $E X U_{i, t}$-that is, an episode of exuberance must last for at least a fraction $\frac{\ln (T)}{T}$ for a series of sample size $T$ of consecutive periods. This allows exclusion of very short occurrences. The origination date of the period of exuberance is defined as the first observation for which the BSADF statistic exceeds its critical value, while the termination date corresponds to the first observation for which the BSADF falls below its critical value for a minimum fraction of $\frac{\ln (T)}{T}$ consecutive periods. The consistency of this dating strategy in the presence of one or multiple explosive periods that are periodically collapsing is established in Phillips et al. (2015a,b).

\section{Main Empirical Findings}

Time series showing boom-bust episodes, like real house prices, feature two important properties: First, they are nonlinear (because they burst) and, second, they are explosive during their boom phase. We can draw inferences about the role of financial spillovers by exploiting the second property of periodically-collapsing episodes of exuberance (i.e., of mildly explosive dynamics) using the GSADF approach for detection and date-stamping developed by Phillips et al. $(2015 a, b)$.

We evaluate the performance of the (right-tailed) unit root tests discussed in the previous section to establish a precise chronology of episodes of exuberance in international housing markets. The relevant empirical question becomes: What financial drivers, if any, account for the chronology of exuberance in international housing markets? Our paper's empirical contribution is examining the predictive ability of financial variables on episodes of exuberance suggested by our theory of arbitrage among alternative asset classes and financial spillovers. With the findings at hand, we conclude that there is evidence of financial propagation with nonlinear impacts on the probability of an episode of exuberance occurring.

Our analysis of housing market data is particularly relevant because of the significance of the housing cycle on broad real economic activity-the widespread boom-bust housing cycle that 
preceded the 2008-09 global recession being a prime example. However, we also point out here that our approach is an important one in financial econometrics and generally relevant to monitor a wide range of asset markets and not solely housing.

\subsection{A Chronology of Exuberance in International Real House Prices}

Our empirical investigation is based on cross-country real house price data from the Federal Reserve Bank of Dallas' International House Price Database (Mack and Martínez-García (2011)). Data are at a quarterly frequency and cover 23 (mostly advanced) countries between first quarter 1975 and fourth quarter 2015, with the corresponding country PCE deflator applied. ${ }^{11}$ We detect and date-stamp periods of exuberance for each country's index of real house prices using the GSADF methodology described in section 3.

We set the minimum window size $r_{0}$ to ensure a minimum window of $\left[r_{0} T\right\rfloor=25$ quarterly observations for each house-price time series. This is consistent with the rule-of-thumb of Phillips et al. (2015a,b), i.e. $r_{0}=0.01+\frac{1.8}{\sqrt{T}}$ for our real house price series that have sample size $T$ of 164 observations. Our results from implementing the GSADF approach are based on four lags in the ADF regression, i.e., $k=4$. However, the findings do not appear very sensitive to the choice of $r_{0}$ or the lag length for that matter.

Table 1 reports the GSADF test statistics for the real house price indices of the 23 countries in our dataset, as well as the corresponding finite-sample critical values. These results show that, except for South Korea, there is empirical evidence of exuberance in all other countries in our sample to conventional statistical levels. We detect exuberance at the 10 percent level for France and Israel based on this test, and at either 1 percent or 5 percent statistical significance for all other countries.

\footnotetext{
${ }^{11}$ The national house price indices are those most consistent with the quarterly U.S. house price index for existing single-family houses produced by the Federal Housing Finance Agency. This database can be accessed publicly at: http://www.dallasfed.org/institute/houseprice/
} 
Table 1. Dallas Fed's Real House Prices: GSADF Test Results

\begin{tabular}{llll}
\hline \hline Panel A: GSADF Test Statistics & & \\
\hline Australia & $6.110^{* * *}$ & Japan & $5.013^{* * *}$ \\
Belgium & $3.450^{* * *}$ & S. Korea & -0.130 \\
Canada & $4.061^{* * *}$ & Luxembourg & $5.278^{* * *}$ \\
Switzerland & $4.091^{* * *}$ & Netherlands & $4.064^{* * *}$ \\
Germany & $3.515^{* * *}$ & Norway & $2.533^{* *}$ \\
Denmark & $3.186^{* * *}$ & New Zealand & $3.051^{* * *}$ \\
Spain & $2.408^{* *}$ & Sweden & $5.178^{* * *}$ \\
Finland & $2.357^{* *}$ & U.S. & $4.243^{* * *}$ \\
France & $2.055^{*}$ & S. Africa & $3.807^{* * *}$ \\
U.K. & $3.143^{* * *}$ & Croatia & $2.244^{* *}$ \\
Ireland & $6.781^{* * *}$ & Israel & $1.849^{*}$ \\
Italy & $2.800^{* * *}$ & Aggregate & $2.910^{* * *}$ \\
\hline Panel B: GSADF Critical Values & & \\
\hline $90 \%$ & 1.766 & & 1.766 \\
$95 \%$ & 2.065 & & 2.065 \\
$99 \%$ & 2.670 & 2.670 \\
\hline
\end{tabular}

Notes: ${ }^{*}, * *$, and ${ }^{* * *}$ denote statistical significance at the 10,5 , and 1 percent significance levels respectively. All results are for autoregressive lag length $k=4$.

Sources: Federal Reserve Bank of Dallas' International House Price Database and authors' calculations.

We then establish a chronology of periods of exuberance for each country using the GSADF date-stamping strategy. In so doing, we summarize our findings with a $E X U_{i, t}$ with all countries $i=1, \ldots, 23$ in our sample that takes the value of 1 during an episode of exuberance in real house prices and 0 otherwise, i.e., $E X U_{i, t}=\left\{\begin{array}{l}0, \text { if } B S A D F_{i, t}\left(r_{0}\right)<s c v_{t}^{\alpha}, \\ 1, \text { if } B S A D F_{i, t}\left(r_{0}\right)>s c v_{t}^{\alpha}\end{array}\right.$, where inference about the explosiveness of the process for the country's real house price at observation $t=\left\lfloor r_{2} T\right\rfloor$ is given by comparing the BSADF statistic $\left(B S A D F_{i, t}\left(r_{0}\right)\right)$ against the corresponding $100(1-\alpha) \%$ critical value of the Sup ADF $\left(s c v_{t}^{\alpha}\right)$ based on $t=\left\lfloor r_{2} T\right\rfloor$ observations. Our sample size is $T=$ 164 quarterly observations for each country, and we set the significance level $\alpha$ for datestamping at a conventional 95 percent level.

As noted in section 3, we follow the recommendation of Phillips et al. $(2015 \mathrm{a}, \mathrm{b})$ and Pavlidis et al. (2016) and set a minimum duration for each episode of exuberance in constructing $E X U_{i, t}$ that excludes very short episodes. For our house price time series of $T=164$ quarterly 
observations by country, the minimum duration that we adhere to- a fraction $\frac{\ln (T)}{T}$ of the $T=164$ observations - is five quarters.

Our chronology is illustrated graphically in Chart 1. The GSADF methodology does not detect exuberance for South Korea at conventional statistical levels (as shown in Table 1). While we reject the null for Croatia at the 5 percent significance level, the GSADF date-stamping strategy only detects very short-lived episodes of exuberance that are ultimately dismissed. For all other countries, we detect at least one episode of exuberance and, in fact, two or more episodes appear in nine out of the 23 countries in our sample-Australia, Switzerland, Spain, Finland, United Kingdom, Ireland, Japan, Luxembourg, and New Zealand.

\section{Chart 1. Chronology of Episodes of Exuberance in Real House Prices}

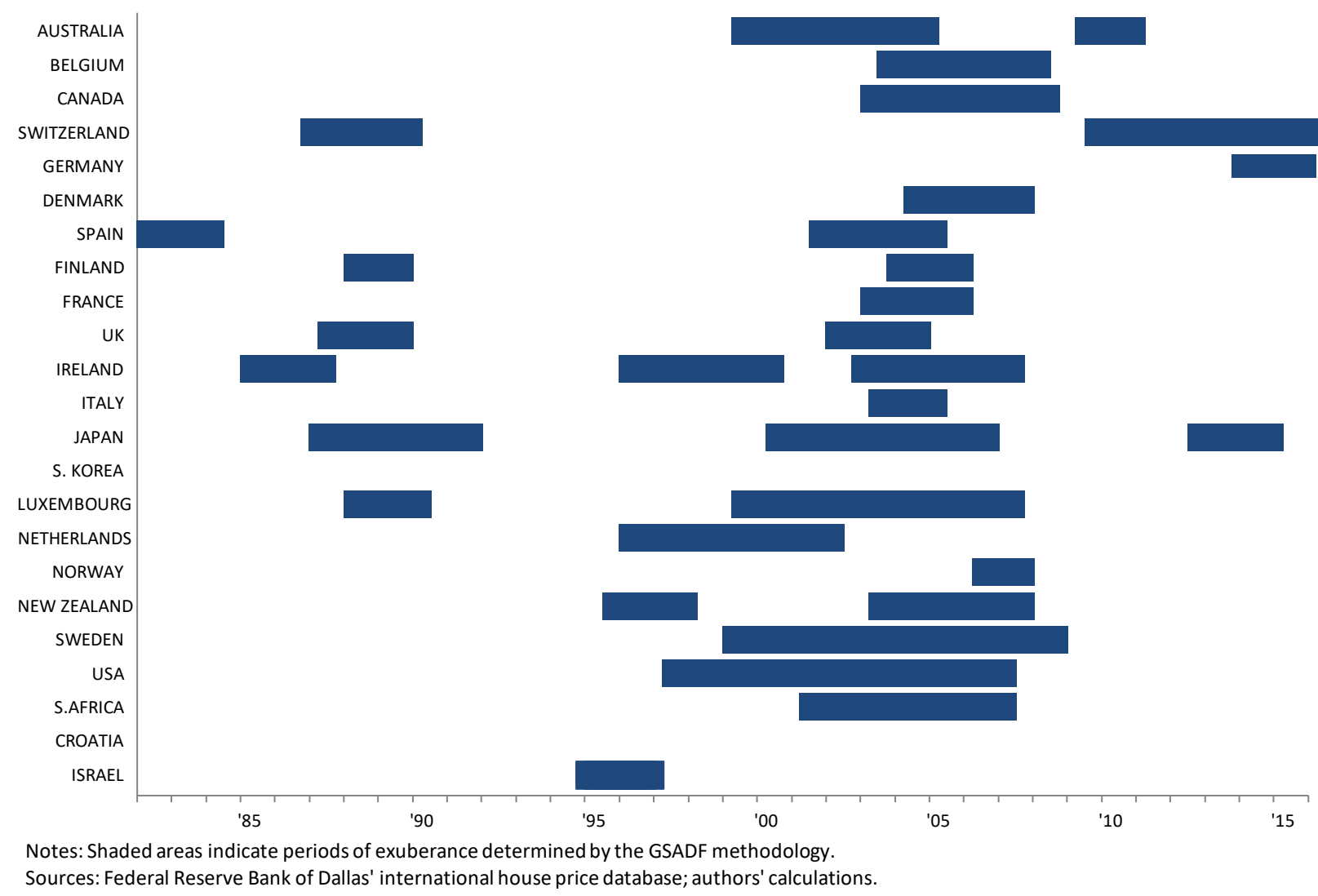




\subsection{Understanding the Impact of Financial Spillovers}

We detect (mildly) explosive behavior in house prices applying recursive right-tailed unit root tests-in particular, the univariate GSADF test that performs well in the presence of multiple periodically-collapsing episodes of exuberance. However, the implications of rejecting the null under the GSADF procedure must still be interpreted with caution because (mildly) explosive episodes do not provide conclusive evidence of non-fundamental behavior, i.e., bubbles. Factors other than bubbles can generate explosive dynamics-such as the type of financial shocks (risk-spread shocks) and financial spillover mechanics investigated in section 2 . Thus, caution should be applied when interpreting our results on international house prices, summarized in Table 1 and Chart 1.

To empirically isolate evidence of non-fundamental behavior in the data, one approach is to derive the fundamental housing price from theory and then test whether deviations between the actual and the fundamentals-based price $\left(P_{t}-P_{t}^{*}\right)$ display mildly explosive behavior. ${ }^{12}$ The drawback of this strategy is the presumption that the correct model is applied to describe the fundamental-based price $\left(P_{t}^{*}\right)$. Omitted variables, measurement error in fundamentals, or simply model misspecification can bias the interpretation of (mildly) explosive behavior tests simply because rejecting the null may indicate the presence of rational bubbles in the data, some form of misspecification, or both (Flood and Garber (1980); Hamilton and Whiteman (1985); Gurkaynak (2008)). This is an example of the well-known joint-hypothesis testing problem.

We adopt an alternative strategy. Our identifying assumption does not impose a particular model tying fundamentals to house prices, but instead relies on a generic implication that holds true for a large class of asset-pricing models of housing: (Mildly) explosive dynamics arising from non-fundamental behavior ought to be unpredictable by their nature, while those that spill over from fundamentals such as financial variables must be predictable. The logic of our analysis is that episodes of (mildly) explosive dynamics such as those shown in Chart 1, if they

\footnotetext{
${ }^{12}$ Based on the rational-expectations solution to the present-value model implied by the difference equation (9) in section 2: a fundamental component, $P_{t}^{*}$, and a periodically-collapsing rational bubble, $B_{t}$, such that $P_{t}=P_{t}^{*}+B_{t}$ (Blanchard and Watson (1982); Sargent (1987); Diba and Grossman (1988a, 1988b); Evans (1991)).
} 
are non-fundamental driven, could only be anticipated by their precedents in previous periods and not necessarily by any fundamentals.

To implement our strategy, we first use the date-stamping approach recommended by Phillips et al. (2015a,b) and Pavlidis et al. (2016) under the GSADF methodology to establish the timeline of episodes of exuberance in international real house prices seen in Chart 1 . Then, we employ a dynamic logit model with lagged instances of exuberance to assess the in-sample predictive ability of financial variables suggested by our theory of financial spillovers and other well-known housing-market and macro fundamentals. This strategy partly mitigates the inconclusive nature of tests of (mildly) explosive behavior by allowing evaluation of the predictive ability of fundamentals related to our financial spillovers theory. ${ }^{13}$

The dependent variable of the logit model is a dummy variable $E X U_{i, t}$ for all countries $i=$ $1, \ldots, 23$ that takes the value of 1 during an episode of exuberance in real house prices and 0 otherwise, as indicated in subsection 4.1. The dynamic logit is then expressed as

$$
P\left(E X U_{i, t}=1 \mid E X U_{i, t-1}, x_{i, t}^{\prime}\right)=\operatorname{logistic}\left(E X U_{i, t-1} \beta_{\text {exu }}+x_{i, t}^{\prime} \beta_{x}\right),
$$

where logistic (.) refers to the logistic $(0,1)$ cumulative distribution function. The model includes a dummy for one-quarter lagged exuberance $E X U_{i, t-1}$ to model the persistence of explosiveness and a vector $x_{i, t}^{\prime}$ of observable fundamentals used as predictors for each of the countries $i=1, \ldots, 23$ in our dataset. If explosiveness in the data results only from nonfundamental behavior, we expect the likelihood of identifying a period of (mildly) explosive behavior in-sample to be a function solely of lagged exuberance $E X U_{i, t-1}$. We augment this simple dynamic logit model with the vector of observed fundamentals $x_{i, t}^{\prime}$ to evaluate the extent of fundamental-based explosiveness and financial spillovers.

\footnotetext{
${ }^{13}$ With this strategy, we evaluate empirically the contribution-if any-of specific fundamentals to explain the observed patterns of (mildly) explosive behavior. Still, evidence that observed fundamentals are not statisticallysignificant does not establish that episodes of exuberance in-sample must arise from rational bubbles due to possible omitted variables, measurement error, etc. We only argue that observed fundamentals for which we reject the null appear to explain some of the evidence of (mildly) explosive behavior that we detect and datestamp in the data.
} 
The predictors in $x_{i, t}^{\prime}$ include quarter-over-quarter changes in real personal disposable income per capita from the Federal Reserve Bank of Dallas' International House Price Database, capturing a key housing-demand-side fundamental that is viewed as anchoring the housing market over the long-run. Other predictors are the unemployment rate, real quarter-overquarter GDP growth and headline quarter-over-quarter CPI inflation, which are indicators of the national business cycle; the global measure of real economic activity proposed by Kilian (2009) and West Texas Intermediate oil prices deflated with U.S. headline CPI to account for the state of the global business cycle.

Among the predictors in $x_{i, t}^{\prime}$ we also include financial variables most directly related to our theory of financial spillovers. These include the spread between the long- and short-term interest rates (which proxies the slope of the yield curve and indicates market expectations of future policy rates); long-term interest rates net of realized headline CPI inflation (to proxy for real mortgage rates and provide a financial measure of the opportunity costs of investing in housing); and quarter-over-quarter changes in stock market valuations deflated with the corresponding CPI (in order to incorporate an alternative asset class that directly influences households' financial wealth).

Furthermore, we also consider propagation through domestic and external borrowing, including in $x_{i, t}^{\prime}$ the quarter-over-quarter changes in credit to the private sector and in the current account deflated with the CPI as well as the current-account-to-GDP ratio. These later items recognize that an expansion of private credit or capital inflows from abroad can lead to asset price and housing boom and busts. We also investigate the predictive ability of factors that can broadly affect the economically-relevant risk-spreads in financial markets. Similarly, we include in $x_{i, t}^{\prime}$ macro volatility (Chicago Board Options Exchange' VIX) and measured policy uncertainty (from PolicyUncertainty.com) - which are thought to be priced into the risk-spreads for discounting housing. Due to data availability, we proxy measured policy uncertainty with the corresponding series for U.S. policy uncertainty.

Our full dataset runs from first quarter 1986 until fourth quarter 2015. To specify the benchmark panel dynamic logit model, we start with a general specification including all our 
explanatory variables and fixed-effects, with bootstrapped standard errors. This model is sequentially reduced by deleting the insignificant variable with the highest $p$-value following each iteration until all remaining variables appear statistically significant. We report this benchmark specification in Column M1 in Table 2, which includes two financial variables directly relevant to our theory of financial spillovers-the spread between long- and short-term interest rates, to proxy the yield curve slope, and quarter-over-quarter changes in stock market valuations deflated with the corresponding $\mathrm{CPI}$, as an alternative asset class return proxy directly tied to households' financial wealth. Apart from these financial variables, we find evidence that fundamentals largely related to housing demand also have predictive power insample. This result suggests that explosiveness in housing fundamentals partially shows up during instances of exuberance in real house prices. It is also consistent with the theory of spillovers through financial arbitrage laid out in section 2.

We also report in Table 2 the benchmark model (M1) under alternative estimation strategies. Column M2 implements a dynamic pooled logit model with the same predictors as M1, a constant, and-country-clustered standard errors. Similarly, Column M3 estimates the benchmark model with the same predictors as M1, random-effects, and country-clustered standard errors. Columns M4 and M5 estimate the same specification as M2 and M3, respectively, but using the probit instead of the logit framework for the estimation. The interpretation of the results for alternatives M2-M5 may vary a bit, yet the key message remains on the statistical significance and sign of the four fundamental variables included in $M 1$, the interest rate spread and real stock market growth in particular.

These results support the view that the spread of the yield curve-and to a lesser extent, real stock market growth-appear to have some predictable power in-sample. We conclude that apart from lagged exuberance, the key explanatory variables are alternative investment asset classes that can lead to financial spillovers and propagation (which apart from the yield spread is captured by real stock market valuations) and real personal disposable income per capita and inflation (which play a substantial role in mapping housing demand). 
Table 2. Estimation Results for the Panel Dynamic Logit and Probit Models

\begin{tabular}{lccccc}
\hline \hline & & Logit & \multicolumn{2}{c}{ Probit } \\
\hline Lagged exuberance & M1 & M2 & M3 & M4 & M5 \\
Interest rate spread & $7.02^{* * *}$ & $7.56^{* * *}$ & $7.56^{* * *}$ & $3.97^{* * *}$ & $3.97^{* * *}$ \\
Real stock growth & $0.31^{* * *}$ & $0.29^{* * *}$ & $0.29^{* * *}$ & $0.12^{* * *}$ & $0.12^{* * *}$ \\
RPDI per capita growth & $0.04^{* * *}$ & $0.03^{* * *}$ & $0.03^{* * *}$ & $0.01^{* * *}$ & $0.01^{* * *}$ \\
CPI inflation rate & $0.45^{* * *}$ & $0.39^{* * *}$ & $0.39^{* * *}$ & $0.18^{* * *}$ & $0.18^{* * *}$ \\
\hline Fixed-effects & $-0.15^{* * *}$ & $-0.15^{* * *}$ & $-0.15^{* * *}$ & $-0.07^{* * *}$ & $-0.07^{* * *}$ \\
Random-effects & Yes & -- & -- & -- & -- \\
Constant-only & -- & -- & Yes & -- & Yes \\
Country-cluster s.e. & -- & Yes & -- & Yes & -- \\
McFadden's $R^{2}$ & --- & Yes & Yes & Yes & Yes \\
\hline
\end{tabular}

Notes: ${ }^{*}, * *$, and ${ }^{* * *}$ denote statistical significance at the 10,5 , and 1 percent significance levels respectively. All results underlying the detection and date-stamping of exuberance are for autoregressive lag length $k=4$ with the initial window set from first quarter of 1975 to first quarter of 1982. Our strongly balanced panel includes dummies for exuberance on each of the 23 countries in the International House Price Database and nearly complete data on a large selection of covariates covering the period from the first quarter of 1986 to the fourth quarter of 2015. The covariates include growth in real per capita personal disposable income (RPDI), headline CPI inflation, interest rate spreads, changes in real stock market valuations, changes in the West Texas Intermediate index of oil prices deflated with U.S. CPI, the U.S. economic policy uncertainty index from Policy Uncertainty.com, the CBOE market volatility index (VIX extended with the VOX, old method data), and other standard macro variables (real GDP growth, the unemployment rate, long-term rates net of realized CPI inflation, private real credit growth, the current-account-to-GDP ratio, growth in the real current account, and the measure of global economic conditions of Kilian (2009)).

We fit a dynamic panel logit model with fixed-effects and bootstrapped standard errors (s.e.) (M1). We report the results of a parsimonious specification of this benchmark after recursively eliminating the non-statistically significant variables with the highest $p$-values one by one. Our benchmark (M1), apart from lagged exuberance, only includes real per capita personal disposable income (RPDI) growth, headline CPI inflation, interest rate spreads, and changes in real stock market valuations. We also report results for a dynamic panel logit with the same covariates as M1, a constant, and country-clustered s.e. (M2); a dynamic panel logit with the same covariates as M1, random-effects, and country-clustered s.e. (M3); a dynamic panel probit with the same covariates as M1, a constant, and country-clustered s.e. (M4); and a dynamic panel probit with the same covariates as M1, randomeffects, and country-clustered s.e. (M5).

Sources: Federal Reserve Bank of Dallas' International House Price Database, National Sources (Central Banks and Statistical Offices), Bank for International Settlements, Wall Street Journal, Kilian (2009), Chicago Board Options Exchange (CBOE), PolicyUncertainty.com, Haver Analytics, and authors' calculations. 
These findings, based on the available international evidence, reinforce our key theoretical prediction that financial spillovers play a substantial role in the occurrence of episodes of exuberance in housing markets. We argue that time-variation in the spreads is an important factor in explaining (mildly) explosive behavior in real house prices across a large selection of countries. The mechanism is consistent with the theory of financial spillovers presented in section 2-episodes of explosiveness arise from time-variation in the discount factor and this, in turn, appears largely driven by the spreads in interest rates, which price an important timevarying risk-premium. However, financial spillovers do not occur solely through bond markets as indicated by our observed interest rate spread but also through other asset classes prominent in the portfolios of households and investors (notably stocks).

Finally, we report the evidence on the conditional predictive margins for both interest rate spreads and real stock market growth in Chart 2 (when fixed-effects are set to zero). The findings shown in these plots suggest that higher interest spreads tend to be associated with a larger probability of exuberance in housing markets conditional on no-exuberance in the preceding period. This is consistent with the illustration of an unanticipated risk-spread shock and its transmission effects into explosiveness of real house prices. In turn, we also find no significant role for interest rate spreads on the probability of exuberance whenever there is evidence of exuberance in the previous period. Our findings for real stock market growth are analogous in this regard to those obtained with the spread. This showcases that the mechanism at play through financial spillovers can be powerful and act as a trigger to generate explosive dynamics in real house prices. Thus, we recognize theoretically and empirically that financial spillovers can be crucial for monitoring developments in housing markets. 
Chart 2. Conditional Predictive Margins for the Financial Variables Conditional on Lagged Exuberance with 95\% Confidence Intervals (Benchmark Model M1)
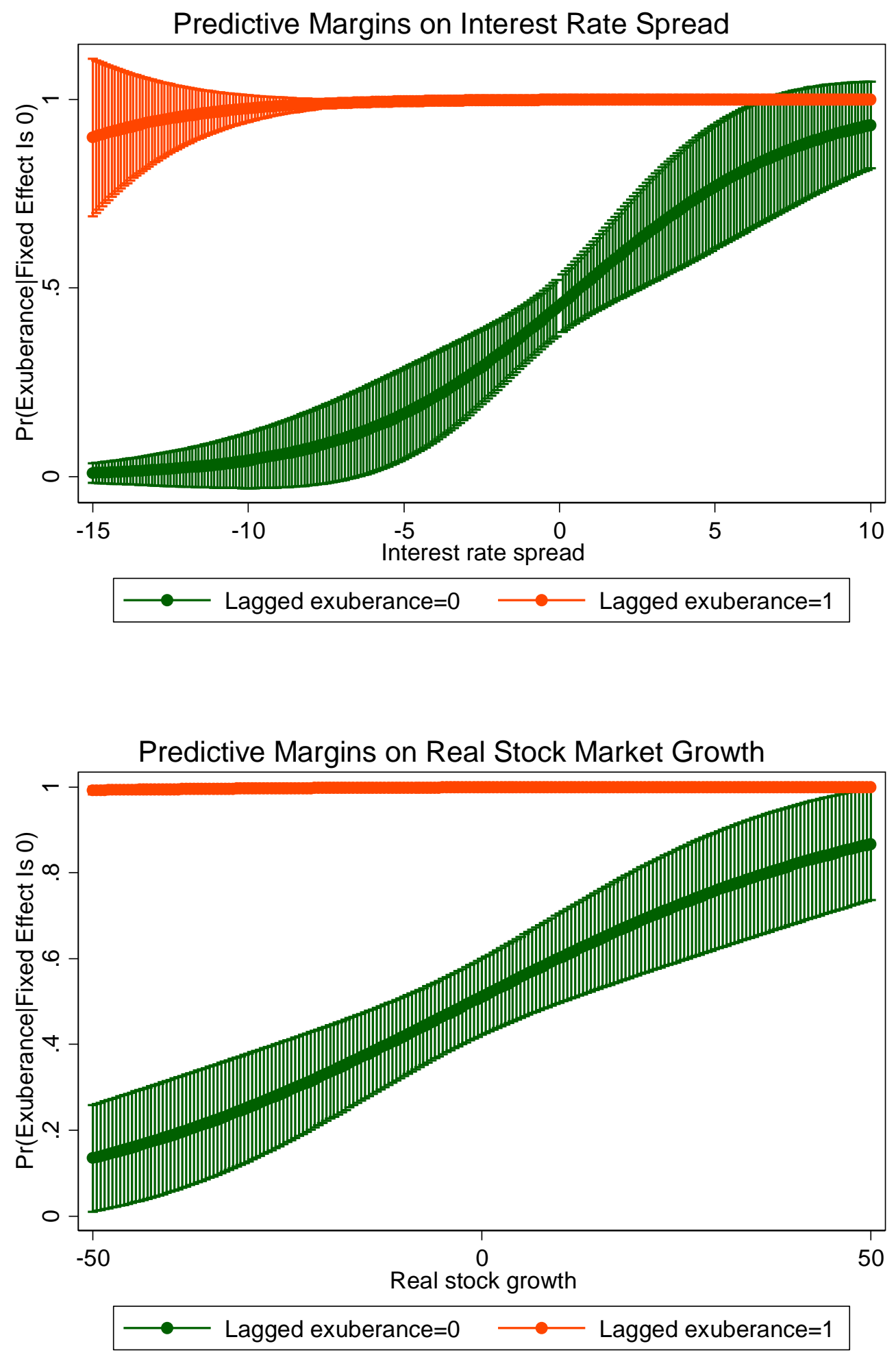


\section{Concluding Remarks}

The relevance of financial variables and financial spillovers for detecting periods of exuberance (mildly explosive) was explored, using real house price data from the Federal Reserve Bank of Dallas' International House Price Database (Mack and Martínez-García (2011)). We find that by exploiting financial variables and particularly interest rate spreads and the evolution of the stock market, we can more successfully monitor the emergence of such episodes in housing markets. Our findings also suggest that financial spillovers and asset-market fundamentals are amongst the deep causes of the mildly explosive behavior detected in asset prices (housing in particular) by recursive right-tailed unit root tests.

We provide both a stylized model of financial spillovers as well as empirical evidence of the spillover effects arising from alternative investment opportunities. Thus, we recognize that the collection and analysis of financial data and financial spillovers can be of crucial importance when monitoring housing market developments across different economies. More generally, this may warrant increased attention to financial conditions broadly, but also a more thorough assessment of fundamentals in monitoring mildly explosive real house price behavior. Our analysis here suggests that, indeed, non-fundamental behavior (bubbles) is not the sole explanation for the periods of exuberance observed in the international housing market data.

Finally, the existing literature indicates that the GSADF test is substantially more powerful than the SADF test and, even more so than the standard (right-tailed) ADF test. The recursive implementation over many subsamples appears key for this result. However, detecting mildly explosive behavior-let alone evidence of explosiveness that arises from a bubble-remains a fertile area of research. More research on improving the available toolkit for detection (and date-stamping) such episodes in asset markets could enhance our ability to monitor housing markets. 


\section{References}

Anderson, T. W., 1959. On asymptotic distributions of estimates of parameters of stochastic difference equations. Annals of Mathematical Statistics 30 (3), 676-687.

https://doi.org/10.1214/aoms/1177706198

Blanchard, O., Watson, M., 1982. Crisis in the economic and financial structure: Bubbles, bursts, and shocks. Chapter: Bubbles, rational expectations, and financial markets, 295-315. Watchel ed., Lexington Books, Lexington, Mass.

Boswijk, H.P., Klaassen, F., 2012. Why frequency matters for unit root testing in financial time series. Journal of Business and Economic Statistics 30 (3), 351-357.

https://doi.org/10.1080/07350015.2011.648858

Campbell, J.Y., Perron, P., 1991. Pitfalls and opportunities: What macroeconomists should know about unit roots. NBER Macroeconomics Annual (vol. 6), eds. O. J. Blanchard and S. Fisher, Cambridge, MA: The MIT Press. https://www.journals.uchicago.edu/doi/10.1086/654163

Choi, I., 1992. Effects of data aggregation on the power of tests for a unit root. Economics Letters 40 (4), 397-401. https://doi.org/10.1016/0165-1765(92)90133-j

Clayton, J., 1996. Rational expectations, market fundamentals and housing price volatility. Real Estate Economics 24 (4), 441-470. https://doi.org/10.1111/1540-6229.00699

Diba, B.T., Grossman, H.I., 1988a. Explosive rational bubbles in stock prices? American Economic Review 78 (3), 520-530.

Diba, B.T., Grossman, H.I., 1988b. The theory of rational bubbles in stock prices. Economic Journal 98 (392), 746-754.

Dickey, D.A., Fuller, W.A., 1979. Distribution of the estimators for autoregressive time series with a unit root. Journal of the American Statistical Association 74 (366a), 427-431.

https://doi.org/10.1080/01621459.1979.10482531

Engsted, T., Hviid, S.J., Pedersen, T.Q., 2016. Explosive bubbles in house prices? Evidence from the OECD countries. Journal of International Financial Markets, Institutions and Money 40, 1425. https://doi.org/10.1016/j.intfin.2015.07.006

Evans, G.W., 1991. Pitfalls in testing for explosive bubbles in asset prices. American Economic Review 81 (4), 922-930.

Evgenidis, A., Tsagkanos, G.A., Siriopoulos, C., 2017. Towards an asymmetric long run equilibrium between stock market uncertainty and the yield spread. A threshold vector error correction approach. Research in International Business and Finance 39 (A), 267-279. https://doi.org/10.1016/j.ribaf.2016.08.002

Flood, R.P., Garber, P.M., 1980. An economic theory of monetary reform. Journal of Political Economy 88(1), 24-58. https://doi.org/10.1086/260846 
Gordon, M.J., Shapiro, E., 1956. Capital equipment analysis: the required rate of profit. Management Science 3 (1), 102-110. https://doi.org/10.1287/mnsc.3.1.102

Gurkaynak, R., 2008. Econometric tests of asset price bubbles: Taking stock. Journal of Economic Surveys 22 (1), 166-186. https://doi.org/10.1111/j.1467-6419.2007.00530.x

Gyourko, J., Mayer, C., Sinai, T., 2006. Superstar cities. National Bureau of Economic Research, working paper no. 12355. https://doi.org/10.3386/w12355

Hamilton, J.D., Whiteman, C.H., 1985. The observable implications of self-fulfilling expectations. Journal of Monetary Economics 16 (3), 353-373. https://doi.org/10.1016/0304-3932(85)90041$\underline{8}$

Hiebert, P., Sydow, M., 2011. What drives returns to euro area housing? Evidence from a dynamic dividend-discount model. Journal of Urban Economics 70 (2-3), 88-98.

https://doi.org/10.1016/j.jue.2011.03.001

Homm, U., Breitung, J., 2012. Testing for speculative bubbles in stock markets: A comparison of alternative methods. Journal of Financial Econometrics 10 (1), 198-231.

https://doi.org/10.1093/ijfinec/nbr009

Hu, Y., Oxley, L., 2018. Bubbles in U.S. regional house prices: evidence from house price-income ratios at the state level. Applied Economics 50 (29), 3196-3229.

https://doi.org/10.1080/00036846.2017.1418080

Kilian, L., 2009. Not all oil price shocks are alike: disentangling demand and supply shocks in the crude oil market. American Economic Review 99 (3), 1053-1069.

https://doi.org/10.1257/aer.99.3.1053

LeRoy, S., Porter, R.D., 1981. The present-value relation: Tests based on implied variance bounds. Econometrica 49 (3), 555-574. https://doi.org/10.2307/1911512

Mack, A., Martínez-García, E., 2011. A cross-country quarterly database of real house prices: A methodological note. Globalization and Monetary Policy Institute Working Paper no. 99.

December, Federal Reserve Bank of Dallas. https://doi.org/10.24149/gwp99

Magdalinos, T., 2012. Mildly explosive autoregression under weak and strong dependence. Journal of Econometrics 169 (2), 179-187. https://doi.org/10.1016/j.jeconom.2012.01.024

Pavlidis, E.G., Yusupova, A., Paya, I., Peel, D., Martínez-García, E., Mack, A., Grossman, V., 2016. Episodes of exuberance in housing markets: In search of the smoking gun. The Journal of Real Estate Finance and Economics 53 (4), 419-449. https://doi.org/10.1007/s11146-015-9531-2

Perron, P., 1991. Test consistency with varying sampling frequency. Econometric Theory 7 (3), 341-368. https://doi.org/10.1017/s0266466600004503

Phillips, P.C.B., Magdalinos, T., 2007a. Limit theory for moderate deviations from a unit root. Journal of Econometrics 136 (1), 115-130. https://doi.org/10.1016/j.jeconom.2005.08.002 
Phillips, P.C.B., Magdalinos, T., 2007b. The Refinement of econometric estimation and test procedures: Finite sample and asymptotic analysis, Chapter: Limit theory for moderate deviations from a unit root under weak dependence, pp. 123-162. Cambridge University Press, Cambridge. https://doi.org/10.1017/cbo9780511493157.008

Phillips, P.C.B., Shi, S.-P., Yu, J., 2015a. Testing for multiple bubbles: Historical episodes of exuberance and collapse in the S\&P 500. International Economic Review 56 (4), 1043-1078. https://doi.org/10.1111/iere.12132

Phillips, P.C.B., Shi, S.-P., Yu, J., 2015b. Testing for multiple bubbles: Limit theory of real-time detectors. International Economic Review 56 (4), 1079-1134.

https://doi.org/10.1111/iere.12131

Phillips, P.C.B., Yu, J., 2011. Dating the timeline of financial bubbles during the subprime crisis. Quantitative Economics 2 (3), 455-491. https://doi.org/10.3982/qe82

Pierse, R.G., Snell, A.J., 1995. Temporal aggregation and the power of tests for a unit root. Journal of Econometrics 65 (2), 333-345. https://doi.org/10.1016/0304-4076(93)01589-e

Said, S.E.; Dickey, D.A., 1984. Testing for unit roots in autoregressive-moving average models of unknown order. Biometrika 71 (3), 599-607. https://doi.org/10.1093/biomet/71.3.599

Sargent, T.J., 1987. Macroeconomic theory, $2^{\text {nd }}$ edition. Boston: Academic Press.

Shi, S., 2017. Speculative bubbles or market fundamentals? An investigation of U.S. regional housing markets. Economic Modelling 66 (November), 101-111.

https://doi.org/10.1016/j.econmod.2017.06.002

Shiller, R.J., 1981. Do stock prices move too much to be justified by subsequent changes in dividends? American Economic Review 71 (3), 421-436.

Shiller, R.J., Perron, P., 1985. Testing the random walk hypothesis: Power versus frequency of observation. Economics Letters 18 (4), 381-386. https://doi.org/10.1016/0165-1765(85)90058$\underline{8}$

Tsagkanos, G.A., Siriopoulos, C., 2015. Stock markets and industrial production in North and South of Euro-zone: Asymmetric effects via threshold cointegration approach. Journal of Economic Asymmetries 12 (2), 162-172. https://doi.org/10.1016/j.jeca.2015.07.001

West, K.D., 1987. A specification test for speculative bubbles. Quarterly Journal of Economics 102 (3), 553-580. https://doi.org/10.2307/1884217

White, J.S., 1958. The limiting distribution of the serial correlation coefficient in the explosive case. Annals of Mathematical Statistics 29 (4), 1188-1197. https://doi.org/10.1214/aoms/1177706450 
Yusupova, A., Pavlidis, E.G., Paya, I., Peel, D.A., 2017. Exuberance in the U.K. regional housing markets. Lancaster University Working Paper 012. 


\section{Appendix. Recursive Implementation of the Right-Tailed ADF Tests}

In this paper we implement a right-tailed unit root test designed to detect the presence of periods of mildly explosive behavior within sample. The existing univariate recursive tests include:

\section{ADF}

2. Sup ADF (SADF), see Phillips et al. (2011)

3. Generalized Sup ADF (GSADF), see Phillips et al. $(2015 a, b)$ - which we favor in our analysis here

These right-tailed unit root tests differ crucially on the recursion mechanism used in their implementation. In order to illustrate this, we need to review some notation first. The full sample of $T$ observations is normalized on the interval $[0,1]$. Here, we denote $r_{1}$ and $r_{2}$ as the corresponding fractions of the sample which define the beginning and end of a given subsample such that $0 \leq r_{1}<r_{2} \leq 1$. We denote by $r_{w}=r_{2}-r_{1}$ the window size of the regression estimation, while $r_{0}$ is the required fixed initial window which satisfies that the subsample ending in $r_{2}$ is such that $r_{2} \in\left[r_{0}, 1\right]$ (i.e., $r_{0}$ is the required minimum window size).

The first test is a right-tailed version of the standard ADF unit root test. With the given notation for a generic recursive mechanism, the implementation of the ADF test can be represented graphically simply as follows:

\section{Illustration of the ADF Procedure}

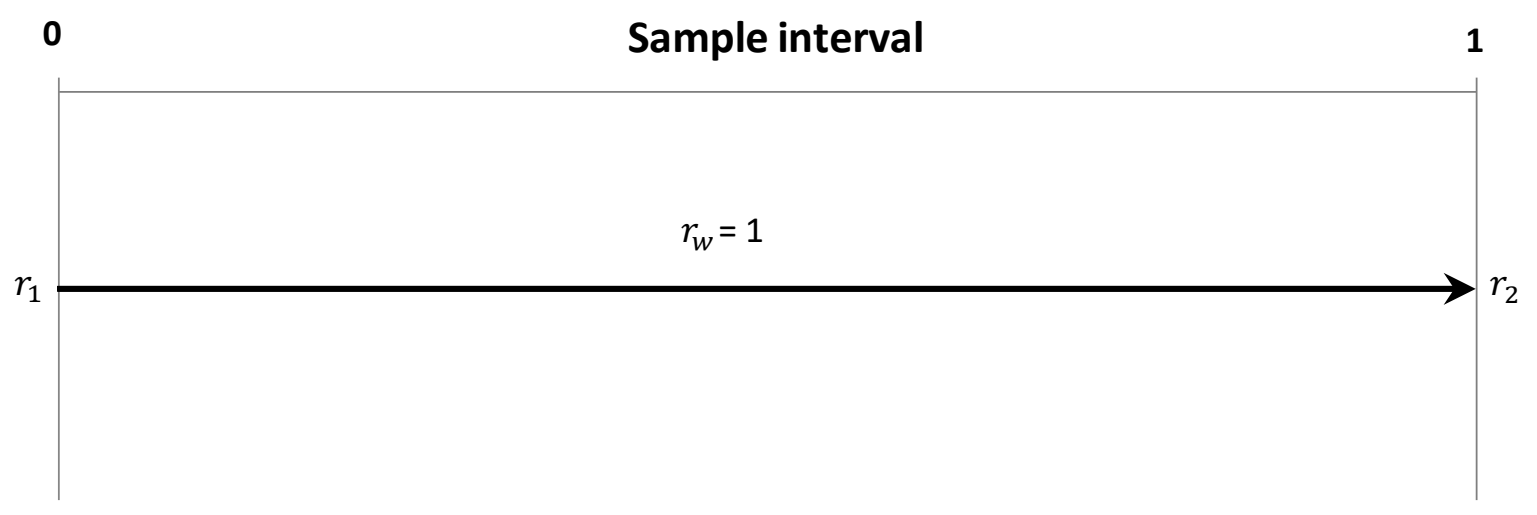

The SADF test is based on a proper recursion mechanism based on the ADF test statistics with an expanding window. The recursion mechanism goes as follows in this case: 


\section{Illustration of the SADF Procedure}

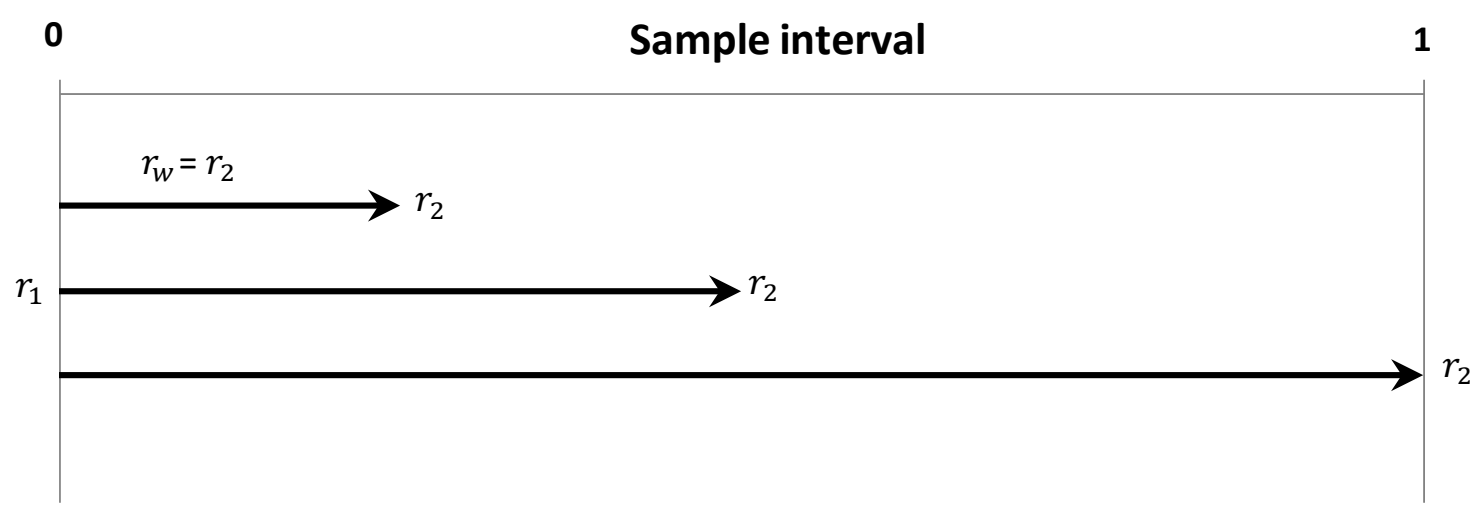

The SADF test suffers from a loss of power in the presence of multiple periodically-collapsing occurrences of mildly explosive behavior. As a preferred alternative, Phillips et al. $(2015 \mathrm{a}, \mathrm{b})$ suggest the GSADF test procedure which is a generalization of the SADF test that allows a more flexible recursion mechanism where the starting point $r_{1}$ varies within the range $\left[0, r_{2}-r_{0}\right] .{ }^{14}$ Formally, the GSADF test recursion can be illustrated as follows:

\section{Illustration of the GSADF Procedure}

0

Sample interval

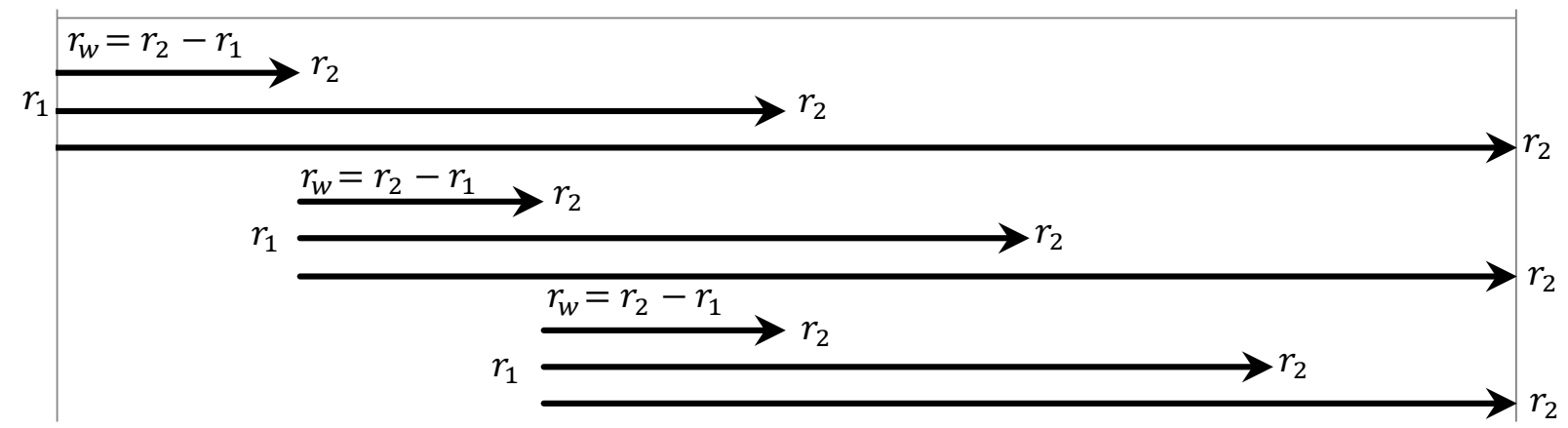

The GSADF recursion mechanism adopts the following strategy: set $r_{1} \in\left[0, r_{2}-r_{0}\right]$ and $r_{2} \in$ $\left[r_{0}, 1\right]$; use $\left[r_{1}, r_{2}\right]$ as a moving window where $r_{w}=r_{2}-r_{1}$ is the corresponding window width for each subsample; and, then, vary $r_{1}$ and $r_{2}$ over the full sample.

${ }^{14}$ The same recursion mechanism is applied in the panel GSADF procedure of Pavlidis et al. (2016). 